\title{
A new effective method for the evaluation of glycated intact plasma proteins in diabetic subjects
}

\author{
A. Lapolla ${ }^{1}$, D. Fedele ${ }^{1}$, R.Seraglia ${ }^{2}$, S. Catinella ${ }^{2}$, L. Baldo ${ }^{1}$, R. Aronica ${ }^{1}$, P. Traldi ${ }^{2}$ \\ ${ }^{1}$ Istituto di Medicina Interna, Cattedra Malattie del Metabolismo, Università di Padova, Padova, Italy \\ ${ }^{2}$ Area di Ricerca CNR, Padova, Italy
}

\begin{abstract}
Summary The molecular weights of plasma proteins from healthy subjects and from patients with well-or badly-controlled diabetes mellitus have been determined by use of a matrix-assisted laser desorption ionization method, representing a highly accurate technique for the determination of the molecular weight of large biomolecules. Using this approach, different molecular weights of human serum albumin have been found for healthy $(66,572-$ 66,694 dalton) and diabetic (66,785-68,959 dalton) subjects. Such differences can be rationalized as being due to the different number of glucose molecules condensed on the protein and/or their further oxida-
\end{abstract}

tion products; in the case of our diabetic patients this number is in the range of 1.4-14.8. The data show the high validity and specificity of the technique, which allows us to evaluate, without any protein degradation procedure, the number of glucose molecules condensed on a specific protein and ascertain the relationship of this number to the physiopathogenetic conditions of the subjects studied. [Diabetologia (1995) 38: 1076-1081]

Key words Protein glycation, human serum albumin, mass spectrometry, laser desorption ionization.
Among the various theories concerning the aetiopathogenesis of chronic diabetic complications, the multifactorial theory is the most widely accepted; it suggests that the tissue damage following metabolic alteration (hyperglycaemia) is favoured by genetic (individual susceptibility) and environmental factors (obesity, hypertension, smoking) [1].

Several studies have shown that hyperglycaemia can cause damage by a series of mechanisms, the

Received: 29 December 1994 and in revised form: 15 March 1995

Corresponding author: Professor D. Fedele, Istituto di Medicina Interna, Cattedra Malattie del Metabolismo, Servizio di Diabetologia, Ospedale Geriatrico, Via Vendramini 7, I-35100 Padova, Italy

Abbreviations: AGE, Advanced glycation end products; FFI, 2-(2 furoyl)-4-(5)-(2 furanyl)-1 $\mathrm{H}$ imidazole; MALDI, matrixassisted laser desorption/ionization; BSA, bovine serum albumin; HSA, human serum albumin; $\mathrm{HbA}_{1 c}$, glycated haemoglobin; Da, dalton; NIDDM, non-insulin-dependent diabetes mellitus; $\mathrm{keV}$, kiloelectron volts; $\mathrm{UV}$, ultraviolet. most important being non-enzymatic protein glycation $[2,3]$. This is usually considered to take place due to the reaction of glucose (or other reducing sugars) with the $\varepsilon$-aminogroup of lysine residues present in the protein chains. This condensation, together with further dehydration and oxidation processes, leads to reactive species which, in turn, are prone to react with $\varepsilon$-aminogroups of lysines belonging to another protein chain [2,3], thereby giving rise to cross-linked products.

The occurrence of extensive protein cross-links in long-lived proteins is reflected in tissue modifications, responsible for long-term diabetic complications [3]. Consequently, attempts have been made to identify the possible markers leading to a more detailed view of the different qualitative and quantitative aspects of the glycation process [4-6].

Most of the methodology is based on the extensive degradation process of the protein (usually acid or enzymatic hydrolysis) and further analysis of its products. This has led to the identification of furosine as a valid early glycation marker [7]. Furthermore, pent- 
Table 1. Clinical and metabolic data

\begin{tabular}{|c|c|c|c|c|c|c|c|}
\hline Subjects & $n$ & Male/female & $\begin{array}{l}\text { Age } \\
\text { (years) }\end{array}$ & $\begin{array}{l}\text { Disease } \\
\text { duration } \\
\text { (years) }\end{array}$ & $\begin{array}{l}\text { Fasting plasma } \\
\text { glucose level } \\
(\mathrm{mmol} / 1)\end{array}$ & $\begin{array}{l}\mathrm{HbA}_{1 \mathrm{c}} \\
(\%)\end{array}$ & $\begin{array}{l}\text { Furosine } \\
\text { ( } \mu \mathrm{g} / \mathrm{mg} \text { protein) }\end{array}$ \\
\hline $\begin{array}{l}\text { Badly-controlled } \\
\text { diabetic patients }\end{array}$ & 20 & $10 / 10$ & $64 \pm 7.6^{\mathrm{a}}$ & $9.3 \pm 8.7$ & $20.2 \pm 4.3^{\mathrm{b}, \mathrm{c}}$ & $10.6 \pm 1.9^{\mathrm{b}, \mathrm{c}}$ & $0.47 \pm 0.08^{b, c}$ \\
\hline $\begin{array}{l}\text { Well-controlled } \\
\text { diabetic patients }\end{array}$ & 10 & $5 / 5$ & $60 \pm 11$ & $12.3 \pm 8$ & $7.96 \pm 1.1^{\mathrm{d}}$ & $7.25 \pm 0.63^{d}$ & $0.33 \pm 0.03^{\mathrm{d}}$ \\
\hline
\end{tabular}

${ }^{\mathrm{a}} p<0.05 ;{ }^{\mathrm{b}} p<0.001$ compared to healthy subjects; ${ }^{\mathrm{c}} p<0.001$ compared to well-controlled diabetic patients; ${ }^{\mathrm{d}} p<0.001$ compared to healthy subjects. Data are mean \pm SD

osidine, first identified in vivo on hydrolysed collagen samples [8] and then confirmed in vitro as originating from the non-enzymatic reaction of pentoses with lysine and arginine, must be considered among the advanced glycation end products (AGEs) responsible for protein cross-links [9]. Some other molecules were considered diagnostic for AGE [10] but further investigations proved that they must be considered artifacts $[11,12]$.

Methods which give definitive information concerning the glycation of the whole protein are of great interest; however, because of the complexity of the biological substrate under investigation, such methods must be highly specific.

Recently, interesting results have been achieved by means of a new mass spectrometric technique called MALDI (Matrix Assisted Laser Desorption Ionization) based on desorption/ionization by laser irradiation of the protein sample, in the presence of suitable matrices [13]. This technique has been applied to the study of in vitro glycation of bovine serum albumin (BSA) [14] and ribonuclease [15], proving its high potential. In fact the molecular weight of the glycated protein was easily ascertained and the glycation kinetics were easily monitored, following the molecular weight increase with respect to incubation time.

Applying this method to in vivo glycated protein studies could lead to the determination of the glycation levels of proteic substrates as well as to the detection of cross-linked proteins; the present study, based on the application of MALDI to plasma proteins of healthy and diabetic subjects, was undertaken precisely for these reasons.

\section{Subjects and methods}

Subjects. Thirty non-insulin-dependent diabetic (NIDDM) patients were studied ( 15 males and 15 females), mean ( \pm SD) age $62.8 \pm 9$ years, (range $43-76$ years), mean disease duration $10.3 \pm 8.5$ years (range $1-32$ years), of whom 20 were in bad and ten in good metabolic control. Fifteen of the patients were being treated with oral hypoglycaemic drugs while the others were receiving insulin treatment. Ten volunteers (four males and six females), mean age $56 \pm 9.6$ years (range $40-$
70 years) with no family history of diabetes and with normal glucose tolerance [16] were studied as control subjects.

On the day of the study fasting plasma glucose, glycated haemoglobin $\left(\mathrm{HbA}_{1 \mathrm{c}}\right)$ and serum furosine were evaluated in all of the subjects; plasma samples for MALDI measurements were also drawn.

All subjects gave their consent to the studies, which were performed in accordance with the Declaration of Helsinki.

Methods. Plasma glucose was evaluated with a glucose-oxidase enzymatic method [17]. $\mathrm{HbA}_{1 \mathrm{c}}$ was determined with a microchromatographic method [18]. Serum furosine was determined according to the method of Schleicher and Wieland [7].

For MALDI measurements $0.5 \mathrm{ml}$ plasma was passed through an Amicon membrane (cutoff 10,000 Da) in order to eliminate free glucose and salts, and then centrifuged at $3000 \mathrm{rev} / \mathrm{min}$ for $30 \mathrm{~min}$ in a Varifuge 3,2 RS (Heraeus, Osterode, Germany). The supernatants were discarded and the samples, after adding deionized water to obtain the initial volume, were further centrifuged for $30 \mathrm{~min}$ at $3000 \mathrm{rev} / \mathrm{min}$. After removing the supernatants the samples were evaporated to dryness under nitrogen and then lyophilized.

The MALDI measurements are based on the interaction of an ultraviolet (UV) laser beam with a solid-state sample constituted by the compound of interest dissolved in a matrix, which exhibits an absorption maximum close to the laser wavelength. The interaction leads to the ionization of the matrix contemporaneously to the fast vaporization of the matrix and analyte.

In the so-formed high-density gas region, ion-molecule reactions easily occur, giving rise to protonated molecules of the compound of interest. Such phenomena are particularly fast $\left(10^{-8} \mathrm{~s}\right)$, so that a particularly fast mass analyser is required; in this context the time-of-flight analyser is one of the most effective.

In the present investigation MALDI measurements were performed on a REFLEX time-of-flight mass spectrometer (Bruker-Franzen Analytic, Bremen, Germany), operating in positive linear mode. Ions, formed by a pulsed UV laser beam (nitrogen laser, $\lambda=337 \mathrm{~nm}$ ), were accelerated at 30 kiloelectron Volts (keV). The UV laser light, with an energy of about $50 \mu \mathrm{J}$, was focussed onto the sample, using a variable focal diameter from $100-300 \mu \mathrm{m}$. In this case a laser power attenuation of $50 \%$ was used. The matrix used was sinapinic acid, dissolved in acetonitrile/water $(50 / 50 \mathrm{v}: \mathrm{v})$ at a concentration of about $5 \times 10^{-3} \mathrm{~mol} / \mathrm{l}$. Plasma protein samples were dissolved in water, containing $0.1 \%$ trifluoroacetic acid, in order to obtain a final concentration of human serum albumin (HSA) of about $2 \times 10^{-6} \mathrm{~mol} / \mathrm{l}$. Of this solution $5 \mu \mathrm{l}$ were added to $5 \mu \mathrm{l}$ of the matrix solution and about $1 \mu \mathrm{l}$ of this mixture was deposited on a stainless steel sample holder. The droplet was allowed to dry under a cold air stream before introduction into 

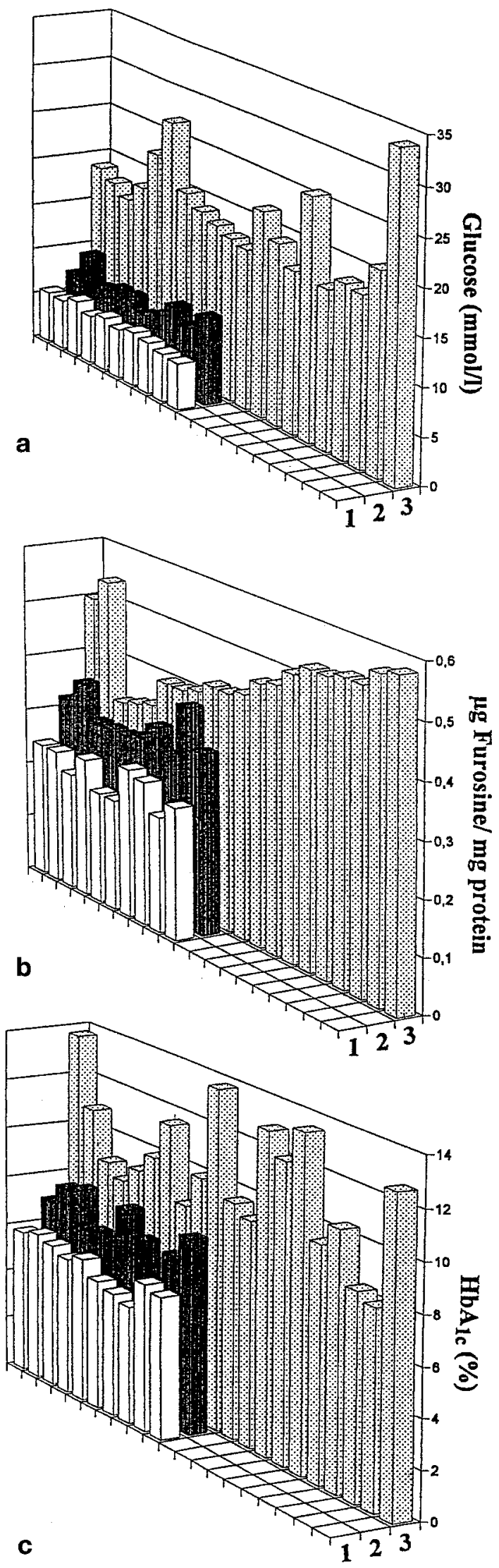

Fig. 1. a Plasma glucose; b furosine levels; c $\mathrm{HbA}_{1 \mathbf{c}}$ determined for 10 healthy (1), 10 patients with well-controlled diabetes ( 2 ) and 20 patients with badly-controlled diabetes ( 3 ) the mass spectrometer. Mass spectra were obtained averaging ten shots; three independent MALDI measurements were made for each sample to evaluate the reproducibility. A mass accuracy ranging from 0.01 to $0.1 \%$ was always present. The experimental molecular weight of pure, essentially fatty acidfree HSA $(66,556 \pm 20 \mathrm{Da})$ purchased from Sigma (St. Louis, Mo., USA) was determined by averaging the values obtained by different MALDI experiments, using BSA $(66,431 \mathrm{Da})$ as an external calibrant and controlling daily. In the spectra shown herein, the mass values calculated by the data system will be reported as usual.

\section{Statistical analysis}

The Student's $t$-test for unpaired data and linear regression was used for statistical analysis. Our results are expressed as mean $\pm S D$.

\section{Results}

The plasma glucose, $\mathrm{HbA}_{1 \mathrm{c}}$ and furosine mean $\pm \mathrm{SD}$ values for the subjects studied are reported in Table 1 . These parameters were significantly higher in the diabetic patients compared with control subjects; moreover diabetic patients in bad metabolic control had higher mean values when compared to patients in good metabolic control. The distribution of the plasma glucose levels, $\mathrm{HbA}_{1 \mathrm{c}}$ and furosine can be seen in Figure 1.

Figure 2a shows a MALDI spectrum of the plasma proteins of the healthy subject A; HSA is responsible for the most abundant peak at 66,680 Da.

The MALDI mass spectrum of plasma protein of the diabetic patient 4 is shown in Figure $2 \mathrm{~b}$. A clear difference in the molecular weight of HSA and other proteins is observed. An intense peak at $68,033 \mathrm{Da}$ is shown, corresponding to a difference in mass compared to HSA of the normal subject A of 1,353 Da.

All the results concerning the mass measurements obtained for the subjects are reported in Table 2 in which the molecular weight of HSA, $\triangle \mathrm{M}$ values and the corresponding number of glucose molecules condensed on the protein are shown. The highest molecular weight values for the patients with badly-controlled diabetes must be emphasized. This tendency may be observed by comparison of $\Delta M$ values, defined as the difference in molecular weight between plasma HSA from the studied subjects and standard HSA. Figure 3 shows that meaningful differences in the $\Delta \mathrm{M}$ values are present between healthy and diabetic subjects. Furthermore, for the patients with badly-controlled diabetes, wide differences in $\Delta \mathrm{M}$ values are observed. 

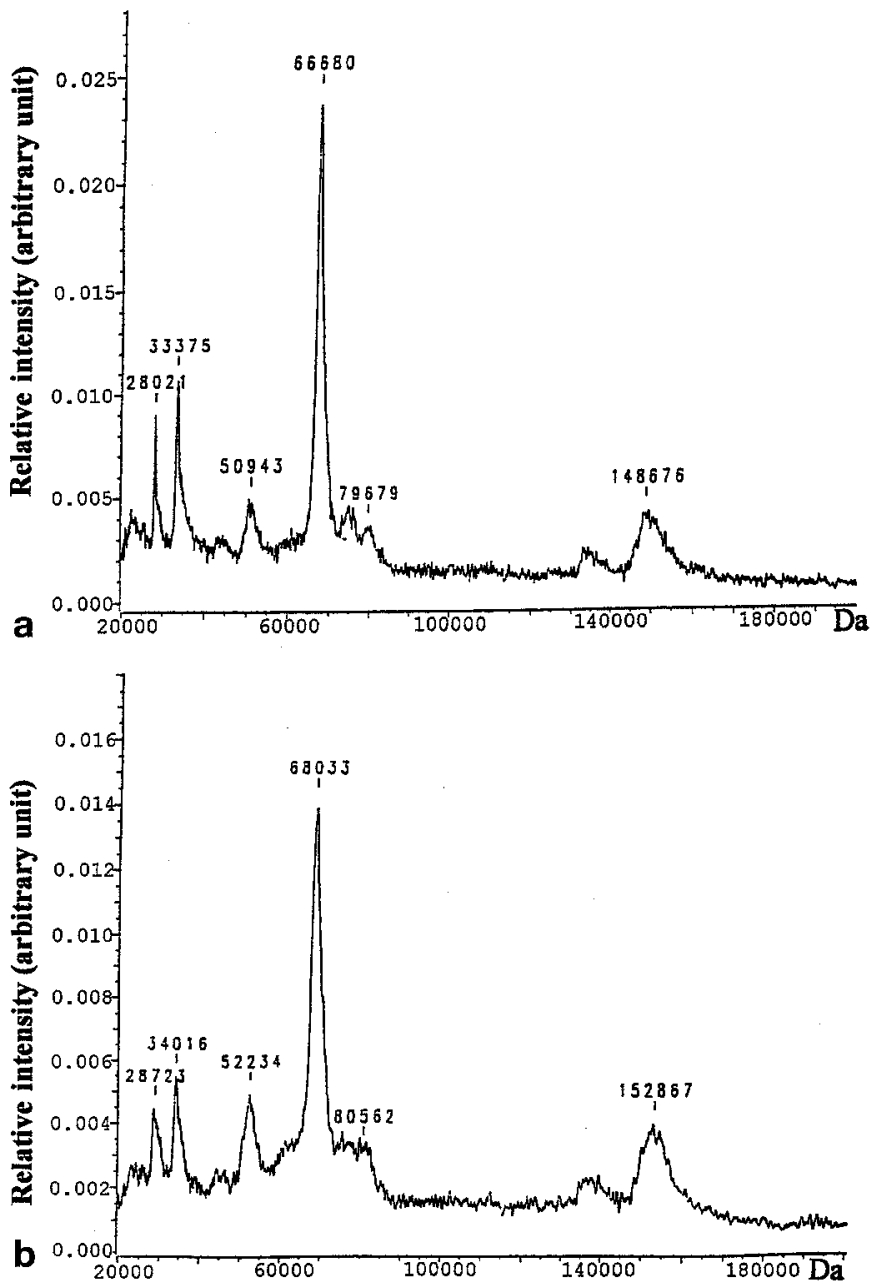

Fig. 2. (a,b) MALDI spectra of plasma protein fractions ob tained from; a healthy subject A; b badly-controlled diabetic patient 4 . The mass values reported on the spectra are those directly determined by the instrument, with a mass accuracy of $0.01-0.1 \%$

\section{Discussion}

The relevance of non-enzymatic protein glycation in aging and diabetes is well known [1-4] and up to now its extent has usually been evaluated by measurements of plasma glucose, furosine and $\mathrm{HbA}_{1 \mathrm{c}}$ levels. These parameters reflect different periods of metabolic control; plasma glucose is the expression of glycaemia at the time of examination, furosine reflects the metabolic control of the 2 weeks preceding the evaluation and $\mathrm{HbA}_{1 \mathrm{c}}$ is the expression of metabolic control in the 2 months preceding the evaluation. Thus, from the data reported in Table 1 and Figure 1, we may conclude that patients with well-controlled diabetes had been so for at least 2 months, while the other patients had badly-controlled diabetes not only on the day of the study, but also for the 2 preceding months. However, what must be emphasized is that such parameters can be related to the protein glycation but cannot give the real level of glycation of selected proteins. In fact, the present study was undertaken to perform such measurements, based on MALDI, a technique which allows the determination of the molecular weight of biomolecules up to $300,000 \mathrm{Da}$.

This approach was previously applied in the study of in vitro glycation of BSA [14] and ribonuclease [15], which assured its validity. The high specificity of the method overcomes the different separative procedures necessary for the isolation of the protein of interest as well as its further manipulation. In fact, the only other procedure employed on the plasma samples in the present investigation was their passage through an Amicon membrane.

As an example, the MALDI spectrum of the whole plasma protein fraction obtained for the healthy subject $A$ is shown in Figure 2a. It can be considered a valid mapping method of the different proteins present in the plasma; the most abundant peak, at $66,680 \mathrm{Da}$, is due to HSA, while the species detected at around $150,000 \mathrm{Da}$ could arise from $\gamma$-globulins. The ions at 79,679 Da are probably due to prothrombine. Because of its higher abundance, we focussed our attention on HSA and proved its identity by comparison with a standard HSA sample. This gave rise to only two peaks, the most abundant of which is at $66,680 \mathrm{Da}$ (corresponding to the HSA protonated molecule) and a smaller one at $33,375 \mathrm{Da}$ due to a double protonated HSA molecule and detected also in the plasma protein spectrum shown in Figure 2 a.

The analysis by MALDI of a plasma protein sample from a diabetic patient shows a clear increase in the molecular weight of HSA, and this result should be explained by the occurrence of protein glycation. As an example, the MALDI spectrum obtained for the patient with badly-controlled diabetes (patient 4) is reported in Figure $2 b$. The peak due to HSA is shifted at $68,033 \mathrm{Da}$, corresponding to a molecular weight increase of $1,353 \mathrm{Da}$ with respect to that of healthy subject $A$.

This mass increase $(\Delta \mathrm{M})$ can be assigned to a number of glucose molecules which reacted with the $\varepsilon$ amino group of lysines present in the protein skeleton and to their possibile oxidative modifications according to the Amadori proposals $[15,19]$.

The MALDI measurements performed on all of the subjects considered are reported in Table 2, and looking at the $\Delta \mathrm{M}$ distribution (Fig. 3 ), what is immediately seen is the strongest difference between the results from the healthy subjects, and those with well-controlled and badly-controlled diabetes. While in the case of plasma glucose, furosine and $\mathrm{HbA}_{1 \mathrm{c}}$ levels, the values related to the first two classes of subjects were quite close (even if significantly different), in the case of $\Delta \mathrm{M}$ values such differences are more than meaningful, the values of healthy subjects in the majority of cases equalling zero.

The $\Delta \mathrm{M}$ value ranges, in the patients with badlycontrolled diabetes, from 439 to $2,403 \mathrm{Da}$. If we con- 
Table 2. MALDI data for the subjects under investigation

\begin{tabular}{|c|c|c|c|c|}
\hline & & $\begin{array}{l}\text { Plasma HSA } \\
\text { molecular } \\
\text { weight (Da) }\end{array}$ & $\begin{array}{l}\Delta \mathrm{M}^{\mathrm{a}} \\
(\mathrm{Da})\end{array}$ & $\begin{array}{l}\text { Glucose } \\
\text { units }\end{array}$ \\
\hline Healthy subjects & $\begin{array}{l}\text { A } \\
\text { B } \\
\text { C } \\
\text { D } \\
\text { E } \\
\text { F } \\
\text { G } \\
\text { H } \\
\text { L } \\
M\end{array}$ & $\begin{array}{l}66680 \\
66574 \\
66572 \\
66610 \\
66575 \\
66694 \\
66601 \\
66666 \\
66660 \\
66609\end{array}$ & $\begin{array}{r}124 \\
18 \\
16 \\
54 \\
19 \\
138 \\
45 \\
110 \\
104 \\
53\end{array}$ & $\begin{array}{l}1 \\
1 \\
1 \\
1 \\
1 \\
1 \\
1 \\
1 \\
1 \\
1\end{array}$ \\
\hline $\begin{array}{l}\text { Well-controlled } \\
\text { diabetic patients }\end{array}$ & $\begin{array}{r}1 \\
2 \\
3 \\
4 \\
5 \\
6 \\
7 \\
8 \\
9 \\
10\end{array}$ & $\begin{array}{l}66890 \\
66926 \\
66882 \\
66806 \\
66836 \\
66844 \\
66822 \\
66785 \\
66863 \\
67052\end{array}$ & $\begin{array}{l}334 \\
370 \\
326 \\
250 \\
280 \\
288 \\
266 \\
229 \\
307 \\
496\end{array}$ & $\begin{array}{l}2.1 \\
2.3 \\
2 \\
1.5 \\
1.7 \\
1.8 \\
1.6 \\
1.4 \\
1.9 \\
3.1\end{array}$ \\
\hline $\begin{array}{l}\text { Badly-controlled } \\
\text { diabetic patients }\end{array}$ & $\begin{array}{r}1 \\
2 \\
3 \\
4 \\
5 \\
6 \\
7 \\
8 \\
9 \\
10 \\
11 \\
12 \\
13 \\
14 \\
15 \\
16 \\
17 \\
18 \\
19 \\
20\end{array}$ & $\begin{array}{l}68204 \\
67101 \\
66995 \\
68033 \\
67237 \\
67783 \\
67696 \\
68349 \\
67949 \\
68787 \\
67993 \\
68503 \\
68460 \\
67494 \\
68885 \\
67939 \\
68256 \\
67991 \\
66999 \\
68959\end{array}$ & $\begin{array}{r}1548 \\
545 \\
439 \\
1477 \\
681 \\
1227 \\
1141 \\
1793 \\
1393 \\
2231 \\
1437 \\
1947 \\
1904 \\
938 \\
2329 \\
1383 \\
1700 \\
1435 \\
443 \\
2403\end{array}$ & $\begin{array}{r}10.0 \\
3.4 \\
2.7 \\
9.1 \\
4.2 \\
7.6 \\
7.0 \\
11.1 \\
8.6 \\
13.7 \\
8.9 \\
12 \\
11.7 \\
5.8 \\
14.4 \\
8.5 \\
10.5 \\
8.9 \\
2.7 \\
14.8\end{array}$ \\
\hline
\end{tabular}

${ }^{a}$ Calculated on molecular weight of pure HSA obtained by MALDI/MS measurements (molecular weight found $66556 \pm 20 \mathrm{Da})$

sider that the condensation of one glucose molecule on the protein leads to an increase in mass of 162 $\mathrm{Da}$, such values correspond to the condensation on HSA from 3 to 15 glucose units. However, such figures do not take into account the further oxidative modification of glucose, leading to species at lower molecular weight. Hence they must be considered as the minimum number of glucose molecules condensed on the protein. For healthy subjects no variation is present, while for well-controlled patients mass increases corresponding to the condensation of 2-3 glucose units are detectable.

The presence of possible complexes between protein and free glucose can be excluded, due to the sam-

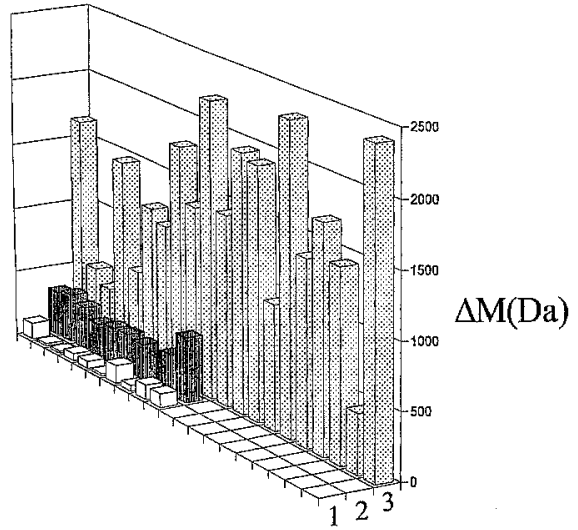

Fig. 3. The $\Delta \mathrm{M}$ values, defined as the difference in molecular weight of plasma HSA of the subjects under study with respect to that of standard HSA, obtained for healthy subjects (1), 10 patients with well-controlled diabetes (2) and 20 with badly-controlled diabetes (3)

ple treatment. The highest number of glucose units condensed on HSA has been found for the badly-controlled patient $20(14.8$, see Table 2). This result is in agreement with the previous findings of Ghiggeri et al. [20] who proved that 16 active sites of HSA are prone to react with glucose molecules. Furthermore Iberg and Flückiger [21] proved, by aminoacid analysis of tryptic digested HSA from a diabetic patient, that ten lysine residues are the most reactive glycation sites. The values we obtained can be justified by the glucose condensation on all these sites and by the further oxidation and dehydration reactions occurring on some of the condensed glucose moieties.

In order to establish the physiological significance of the values here obtained we tested the possible linear relationship between $\Delta \mathrm{M}$ values and the glycation parameters currently employed in diabetes monitoring. Such trends present low linearity $(r=0.84$ for plasma glucose and $\mathrm{HbA}_{1 \mathrm{c}} ; r=0.77$ for furosine) showing that the mass increase determined by MALDI can only with difficulty be related to such parameters. The scarce linearity could be explained by the diverse targets considered in the different measurements. In particular, the high specificity of the MALDI method allows determination of the mass increase present in diabetic subjects (and hence necessarily arising from glycation processes) for HSA and not, as in the case of furosine, for the whole set of plasma proteins; in the case of $\mathrm{HbA}_{1 \mathrm{c}}$ the glycation of a different protein is monitored.

In conclusion, the data discussed above show that the MALDI technique exhibits interesting features in the investigation of protein glycation processes. First of all, it does not require any sample degradation which can lead sometimes to artifacts and requires complex and time-consuming procedures. On the contrary MALDI requires only the sample solution in a suitable matrix: the plasma protein spectra 
shown in Figure 2 are a good example of the large amount of information gained on the whole protein fraction of plasma, with only a minor sample manipulation.

Secondly, MALDI allowed us to evaluate the number of glucose molecules (and/or its oxidation products) condensed on a specific protein, contrary to results obtained by other methods which necessarily lead to a mean value of protein glycation.

The natural evolution of the present work could lead to both the application of the same methodology in a larger population, and also its employment in the study of in vivo glycation kinetics; studies are already in progress along these lines.

Acknowledgement. This work was supported by a CNR-Roma, Progetto Finalizzato Invecchiamento, grant n. 953571.

\section{References}

1. Brownlee M (1990) Advanced products of non-enzymatic glycosylation and the pathogenesis of diabetic complications. In: Rifkin C, Porte D (eds) Diabetes mellitus theory and practice. Elsevier, New York, pp 279-291

2. Brownlee M, Vlassara H, Cerami A (1984) Non-enzymatic glycosylation and the pathogenesis of diabetic complications. Ann Intern Med 101: 527-537

3. Monnier VM, Cerami A (1983) Non-enzymatic glycosylation and browning of proteins in vivo. In: Waller GR, Feather F (eds) The Maillard reaction in foods and nutrition. Am Chem Soc Symp Series 215, Washington DC, pp 431-439

4. Monnier VM (1989) Toward a Maillard reaction theory of aging. In: Baynes JW, Monnier VM (eds) The Maillard reaction in aging, diabetes and nutrition. Alan R Liss Inc. 304, New York, pp 1-22

5. Ledl F (1990) Chemical pathways in the Maillard reaction. In: Finot PA, Aeschbacher HU, Hurrell RF, Liardon E (eds) The Maillard reaction in food processing, human nutrition and physiology. Birkhäuser Verlag, Basel Boston Berlin, pp 19-42

6. Brownlee M, Vlassara H, Cerami A (1988) Advanced glycosylation end products in tissue and the biochemical basis of diabetic complications. N Engl J Med 318: 1315-1321

7. Schleicher E, Wieland OH (1981) Specific quantitation by HPLC of protein (lysine) bound glucose in human serum albumin and other glycosylated proteins. J Clin Chem Clin Biochem 19: 81-87
8. Sell DR, Monnier VM (1989) Structure elucidation of a senescence crosslink from human extracellular matrix. J Biol Chem 264: 21597-21602

9. Sell DR, Lapolla A, Odetti P, Fogarty J, Monnier VM (1992) Pentosidine formation in skin correlates with severity of complications in individuals with long-standing IDDM. Diabetes 41: 1286-1292

10. Pongor S, Ulrich PC, Bencsath FA, Cerami A (1984) Aging of proteins: isolation and identification of a fluorescent chromophore from the reaction of polypeptides with glucose. Proc Natl Acad Sci USA 81: 2684-2694

11. Njorge FG, Fernandes AA, Monnier VM (1988) Mechanisms of formation of putative advanced glycosylation end product and protein cross-link 2-(2-furoyl)-4(5)-(2-furanyl)-1 H-imidazole. J Biol Chem 263: 10646-10652

12. Lapolla A, Gerhardinger C, Pelli B et al. (1990) Absence of brown product FFI in non diabetic and diabetic rat collagen. Diabetes 39: 57-61

13. Karas M, Bahar U, Grießmann U (1991) Matrix assisted laser desorption ionization mass spectrometry. Mass Spectrom Rev 10: 335-357

14. Lapolla A, Gerhardinger C, Baldo L et al. (1993) A study on in vitro glycation processes by Matrix Assisted Laser Desorption Ionization Mass Spectrometry. Biochim Biophys Acta 1225: 33-38

15. Lapolla A, Baldo L, Aronica R et al. (1994) Matrix assisted laser desorption/ionization mass spectrometric studies on protein glycation. 2 . The reaction of ribonuclease with hexoses. Biol Mass Spectrom 23: 241-248

16. National Diabetes Data Group (1979) Classification and diagnosis of diabetes mellitus and other categories of glucose intolerance. Diabetes 28: 1039-1057

17. Hugget A, Nixon DA (1957) Use of glucose-oxidase, peroxidase and $\mathrm{O}$-dianisine in the determination of blood and urinary glucose. Lancet II: $368-370$

18. Schifreen RS, Hickingbothan JM, Bowers GM (1980) Accuracy, precision and stability in measurement of $\mathrm{HbA}_{1 \mathrm{c}}$ by high performance cation exchange chromatography. Clin Chem 26: 466-470

19. Baynes JW (1991) Role of oxidative stress in development of complications in diabetes. Diabetes 40: 405-412

20. Ghiggeri GM, Candiano G, Delfino G et al. (1985) Reaction of human serum albumin with aldose. Carbohydr Res 145: 113-122

21. Iberg N, Flückinger R (1986) Nonenzymatic glycosylation of albumin in vivo. Identification of multiple glycosylated sites. J Biol Chem 261: 13542-13545 